\title{
What seems attractive may not always work well: Evaluative and cardiovascular responses to morality and competence levels in decision-making teams
}

Group Processes \& Intergroup Relations 2018, Vol. 21(1) 73-87 (C) The Author(s) 2016 Reprints and permissions: sagepub.co.uk/journalsPermissions.nav DOI: $10.1177 / 1368430216653814$ journals.sagepub.com/home/gpi

\author{
Anne-Marie van Prooijen, ${ }^{1}$ Naomi Ellemers, ${ }^{2}$ Romy van der Lee, ${ }^{3}$ \\ and Daan T. Scheepers ${ }^{3}$
}

\begin{abstract}
People are particularly attracted to groups that value morality. However, in social and work life, team decision-making sometimes involves balancing moral considerations with achievement goals in ambiguous situations. We examined how the importance attached to morality and competence in experimentally created task teams influenced perceived team attractiveness and motivational responses. Results showed that team attractiveness was fully determined by value attached to morality in a team. However, cardiovascular responses revealed that when actually engaging in a team interaction where unanimous decisions had to be made about competing considerations, value attached to both morality and competence in a team influenced participants' motivational states. Congruence between the value attached to morality and competence elicited adaptive challenge responses, while incongruence between these team features elicited maladaptive threat. These results have important theoretical and practical implications.
\end{abstract}

\section{Keywords}

cardiovascular responses, competence, group decision-making, impression-formation, morality

Paper received 17 August 2015; revised version accepted 16 May 2016.

People are generally attracted to moral groups, task teams, and organizations (Ellemers, Kingma, van de Burgt, \& Barreto, 2011; Leach, Ellemers, \& Barreto, 2007; van Prooijen \& Ellemers, 2015). Yet, although many people are committed to acting in accordance with moral values, they sometimes encounter situations where a trade-off needs to be made between a group decision that can be considered as morally "good," and a competent decision that ensures the effectiveness of the group in terms of task performance or financial success. For example, groups can be confronted in social or work life with decisions where group values collide

\footnotetext{
${ }^{1}$ Vrije Universiteit Amsterdam, The Netherlands

${ }^{2}$ Utrecht University, The Netherlands

${ }^{3}$ Leiden University, The Netherlands
}

\section{Corresponding author:}

Anne-Marie van Prooijen, Faculty of Social Sciences, Department of Communication Science, Vrije Universiteit Amsterdam, De Boelelaan 1105, 1081 HV Amsterdam, The Netherlands.

Email: a.m.vanprooijen@vu.nl 
with economic necessities due to scarcity of group resources (Tetlock, 2003).

Groups may differ in how they tend to respond to such ambiguous situations. That is, some groups are characterized by an emphasis on moral values, in which integrity and honesty are the primary concerns in decision-making. In other contexts, groups might be fully focused on task performance or financial achievement, thereby accepting the possibility that moral considerations have to be adjusted to make this possible. We address these differences in the current research, by examining how the value attached to morality and competence in experimental decision-making teams impacts on perceived team attractiveness and on individual motivational states (indicated by cardiovascular markers) during task completion, in contexts where morality and competence considerations have to be balanced.

\section{Morality as Primary Determinant of Team Attractiveness}

According to social identity theory, people can derive social meaning and value from their membership in groups, teams, and organizations (Tajfel, 1978; see also Ellemers \& Haslam, 2011; Haslam \& Ellemers, 2011). The connection between group features and personal self-views promotes the attraction to groups with positive characteristics as well as the tendency of individual group members to positively evaluate characteristic group features (Tajfel \& Turner, 1979). The competence-related achievements and successes of groups have tended to be considered as the main source of group status and value, in particular in performance contexts relating to education or work (Bettencourt, Dorr, Charlton, \& Hume, 2001). Yet, recent research has revealed that group morality may be just as relevant or an even more important source of group value, even in contexts where performance and achievement are clearly required (Brambilla, Sacchi, Pagliaro, \& Ellemers, 2013; Ellemers, Pagliaro, Barreto, \& Leach, 2008). In fact, compared to competence as well as sociability, group morality has been found to have a stronger impact on the overall evaluation of the group, on group identification, and on group pride in prior research with different types of samples, manipulations, and measures (Leach et al., 2007). Individuals tend to rely on moralityrelated information to form an impression of whether other people's intentions toward them are beneficial or harmful, whereas competencerelated information indicates whether people are capable of successfully pursuing their intentions (Brambilla, Sacchi, Rusconi, Cherubini, \& Yzerbyt, 2012; Fiske, Cuddy, \& Glick, 2007). Thus, both competence and morality concerns should play a role, even in work contexts - where competence (e.g., task performance, economic achievement) is expected to be key. Nevertheless, prior research revealed that-when facing a trade-off between morality and competence in work contexts-people prefer to be included in an organization or a work team that values morality over competence rather than vice versa (van Prooijen \& Ellemers, 2015).

Although several studies have demonstrated the primacy of morality features as a determinant of the attractiveness of groups, little research has focused on the impact of such features on the further responses of individual group members once they are included in such groups. The aims of the current research are twofold. First, we aim to replicate prior work demonstrating the impact of moral group features on perceived team attractiveness, under more controlled (experimental) conditions. Second, we aim to extend previous research by examining how morality and competence group features affect individual group members' motivational states that may operate when collaborating on team tasks. Cardiovascular reactivity will be measured to assess the adaptiveness of the motivational states that are elicited by group morality and competence features.

\section{Motivational Threat Versus Challenge}

The biopsychosocial (BPS) model of arousal regulation (Blascovich \& Mendes, 2000; Blascovich \& Tomaka, 1996) posits that engagement in a 
motivated performance situation (e.g., task performance, playing a game, social interactions) can elicit a motivational state of challenge or threat, which are indicated by distinct patterns of cardiovascular responses. The relation between perceived individual resources (e.g., skills, dispositions, support) and the estimated demands (e.g., required effort, uncertainty, danger) relevant to the performance situation determines the response that is elicited. An adaptive state of challenge emerges when individuals evaluate the resources available to them as meeting or exceeding the demands of the situation. A maladaptive state of threat results when individuals feel unprepared to cope with a situation and evaluate demands of the situation as exceeding the resources available to them.

Physiological challenge and threat responses can be distinguished by comparing cardiac output (CO) - the amount of blood pumped from the heart per minute-and vascular resistance (i.e., total peripheral resistance [TPR]) to a baseline assessment. Challenge is indicated by a dilation of arteries (lower TPR) to accommodate an increase in blood circulation (higher CO), and therefore represents a more efficient mobilization of energy than threat, which is indicated by a constriction of arteries (higher TPR) and no change or a decrease in blood circulation (lower CO; see Blascovich \& Tomaka, 1996, for an overview). However, rather than representing two dichotomous states, challenge and threat should be considered as opposite ends of one bipolar continuum. Consequently, relative differences in motivational states (e.g., greater or lesser challenge or threat) are of significance and are more commonly examined than the absolute occurrence of a single motivational state (Seery, 2011).

Examining on-line emergence of cardiovascular responses provides several advantages over more traditional retrospective self-report measures (Frings, Hurst, Cleveland, Blascovich, \& Abrams, 2012; Nisbett \& Wilson, 1977; Weisbuch, Seery, Ambady, \& Blascovich, 2009). For example, cardiovascular responses can be assessed during team interactions - thereby avoiding the possibly biased evaluation of situations in anticipation or in hindsight. Importantly, cardiovascular responses cannot easily be controlled by participants for self-presentational purposes. Furthermore, in addition to cognitive deliberations, nonconscious and implicit affective processes influence the evaluation of demands and resources within a situation-and therefore whether challenge or threat states are elicited. Whereas relative challenge has been associated with a range of positive outcomes, relative threat has been shown to negatively affect task performance (Blascovich, Mendes, Hunter, \& Salomon, 1999; Blascovich, Seery, Mugridge, Norris, \& Weisbuch, 2004), openness to opposing viewpoints during team decision-making (De Wit, Scheepers, \& Jehn, 2012), and long-term physical health (Blascovich, 2008).

\section{Motivational Responses to Morality and Competence}

Our aim is to relate individual-level threat-challenge responses to team features that inform the individual of the resources available in the situation to meet current task demands. This allows us to unveil how the value attached to morality and competence by other team members impacts individual motivational states in contexts where team consensus needs to be obtained under competing task demands. We examine the possibility that the impact of team morality and competence on ratings of a priori team attractiveness might differ from their impact on the motivational state (indicated by cardiovascular responses) that is elicited once individuals actually engage in a team decision-making task. When people form an a priori impression of the team, they try to anticipate whether their inclusion in this team is likely to be a source of pride and positive identity. In this context, where they focus on how team features might contribute to group-relevant self-views, the morality of the team is more likely to stand out as an important source of value to individual group members than is the competence of the team.

The relative importance of morality in comparison to competence has consistently been 
revealed in various contexts - such as in natural group settings (Leach et al., 2007), experimental task teams (Ellemers, Pagliaro, \& Barreto, 2013), and organizational contexts (van Prooijen \& Ellemers, 2015). For example, previous research has shown that intentions to interact with national in-group and out-group members were driven by their morality levels, but not their competence levels (Brambilla et al., 2013). Likewise, only perceived in-group morality has been shown to affect people's pride in their in-group or their preference to distance themselves from it (Leach et al., 2007). We therefore hypothesize that attraction to the team should be driven primarily by the value other team members attach to morality rather than competence.

However, when engaging with other team members during a joint decision-making task, situational demands - for instance in the form of concrete task requirements that have to be met-are likely to become more prominent. The situational demands of a joint decision-making task tend to depend on the nature of the specific task. Certain tasks might require teams to focus only on competence concerns or only on morality concerns, whereas a balance between these concerns might be preferable in more ambiguous decision-making tasks. In the current research we argue that a discrepancy between the task requirements regarding morality and competence concerns on the one hand and the value attached to these features by team members on the other will increase individual assessments of the situational demands, while it will reduce individual assessments of the available situational resources. A discrepancy between task demands and values of team members is therefore likely to promote a threat response.

In an ambiguous decision-making task, individuals are best equipped to meet the situational demands of a task requesting them to reconcile moral values with competence requirements when there is a balance in the importance their teammates attach to these different concerns. When other team members attach equal value to morality and competence, this represents a relevant resource to individuals who are expected to reconcile both types of concerns in meeting the demands of the joint task. In comparison, when other team members clearly value morality over competence or vice versa, they will be reluctant to take into account the concern that is deemed less important by them in their joint decision-making (Ditto \& Lopez, 1992). This is likely to add to the task demands as experienced by individuals, as they realize they will somehow have to overrule or compensate for this lack of balance in their teammates' concerns to reach an optimal task performance. Thus, we predict that teams in which equal value is attached to morality and competence elicit a more adaptive challenge state in individual team members. In this case the team offers them more resources to meet situational task demands, as they are more likely to support the efforts that try to incorporate both types of concerns in their joint decision. For similar reasons, we predict that individual team members will experience a more maladaptive state of threat in teams in which concerns are less balanced. When other team members clearly prioritize morality over competence or vice versa, this complicates team decision-making. It adds to the situational demands under which individuals have to meet the task requirement to balance competence concerns with moral concerns in joint decisionmaking, as more individual effort is likely to be required while the achievement of desired outcomes is more uncertain. Thus, even though we examine individual-level threat versus challenge responses, we argue that individual assessments of the situational resources and demands relevant to successful task completion are informed by their awareness that other team members are equally willing to consider both these concerns, or will tend to prioritize one over the other.

\section{Method}

\section{Participants}

Seventy-six students (55 females, 21 males) at Leiden University completed the experiment in return for course credit or $€ 8.00$. The age of the participants ranged from 17 to 50 years $(M=20.96$, $S D=4.22)$. 


\section{Design and Procedure}

The hypotheses were tested in a 2 (value attached to morality in the team: high vs. low) x 2 (value attached to competence in the team: high vs. low) between-subjects design. At the beginning of the experiment, physiological sensors to measure cardiac and hemodynamic activity were attached to participants, followed by a 5-minute baseline period. The procedure developed by van Prooijen and Ellemers (2015, Study 3) was followed, where an experimental team task was constructed to examine the impact of team morality and team competence on individual attractiveness ratings. Participants were informed that they-together with two other participants-would complete a task that focused on dilemmas between morality and competence in business contexts. We selected a business context as a suitable setting for the experimental decision-making task, as it has been observed that many businesses are characterized by a complex trade-off between financial and nonfinancial business objectives, in which both morality and competence represent relevant concerns (Clegg, Kornberger, \& Rhodes, 2007; Hahn, Figge, Pinkse, \& Preuss, 2010; Margolis \& Walsh, 2003; Vogel, 2005).

In preparation for the task and as part of the team introduction, participants were asked to complete a brief questionnaire indicating the importance of morality (i.e., their own perceived sincerity, honesty, and trustworthiness) and competence in their own self-views (i.e., their perceived capability, intelligence, and skillfulness; see the Materials section for more details). Their average morality and competence scores would ostensibly be displayed to the other team members and vice versa. The alleged average scores indicating the importance other team members attached to morality and competence were then presented, which in addition were said to be either relatively high or low depending on experimental condition. Next, participants were informed that - in order to get further acquainted with the team-each team member would be asked to record two videos in which they could inform the other team members of their general morality and competence concerns. They were instructed to use this opportunity to indicate the importance they attached to each of these concerns across a range of situations, and to provide a concrete example of such a situation to illustrate their general inclination to display moral and competent behavior. Participants were first presented with four webcam videos displaying behavioral descriptions allegedly provided by their team members. In reality, these were prerecorded videos prepared by confederates. To support the belief that two other team members were present during the experimental session, participants were asked to wait a moment before the first video was presented, as the other team members needed some time to record their videos. We always presented participants with videos of same-gender confederates to control for gender effects; the text of the confederate videos was identical, regardless of gender. Value attached to morality in the team (high vs. low) was manipulated in the first video of each confederate. Both confederates started with a statement that they considered themselves as (quite/ not very) moral. One confederate further elaborated on this by explaining (regularly/never) giving money to charity, and generally (not) being willing to help others, and then gave a concrete example of (not) providing help when this was explicitly requested by a friend. The other confederate revealed that honesty was generally (not) important to him/her, and recounted a particular experience of (not) having been honest about receiving too much change in a store to illustrate this. The two remaining videos also contained behavioral descriptions of the two confederates, this time these were meant to illustrate the value they allegedly attached to competence (high vs. low). Again, both confederates first stated how important competence (quite/not very) was to them in their overall self-views. One confederate then proceeded to describe the relative ease of success (or their relative difficulty to succeed) in their performance at university and at work in comparison to others, to illustrate this. The other confederate first stated that performance was generally (not) important to them, which was 
Table 1. Means, standard deviations, and correlations of the self-report measures.

\begin{tabular}{lllll}
\hline & $M$ & $S D$ & 1. & 2. \\
\hline 1. Team attractiveness & 4.07 & 1.15 & & \\
2. Identification & 3.46 & 1.33 & $.78^{* * *}$ & \\
3. Team commitment & 2.99 & 1.09 & $.65^{* * *}$ & $.61^{* * *}$ \\
\hline
\end{tabular}

Note. $* * * p<.001$

followed by a description of winning (or losing) an important sports match, and their aversion against (or indifference toward) losing in general, to illustrate this general tendency. Participants were then instructed to record their own video with the webcam, describing their own moral and competent behavior indicating to their team members the value they attached to these domains. They were asked to speak for a minimum of 30 seconds in two separate recordings, during which their cardiovascular responses were measured. Manipulation checks and measures of team attractiveness and identification were introduced afterwards.

Subsequently, the team decision-making task was presented, in which participants were required to choose between two business strategies in various dilemma situations (further details in the Materials section). Participants were told that they first had to indicate their personal preferences for each situation, before discussing these with their team members to reach a unanimous group decision on which business strategy to follow in each case. After participants had indicated their personal preferences for each task item, team commitment was assessed. ${ }^{1}$ Responses to all self-report measures were provided on Likert scales ranging from 1 (strongly disagree) to 7 (strongly agree). Descriptive statistics of the selfreport measures are presented in Table $1 .^{2}$ Participants were then asked to use the webcam to describe to their teammates which strategies they had used to determine their personal preferences in the decision-making task-allegedly in preparation of a more extensive group discussion—during which their physiological responses were measured. To support the cover story that they were engaged in an interaction with other team members, participants could see themselves as well as the (prerecorded) faces of the confederates-who were allegedly listening to what they said-during the webcam recording. After completing the webcam recording, participants were informed that the experiment was finished and no further group discussion would take place. We explicitly asked participants to not discuss the true purpose of the experiment with others, and we explained how this disclosure could negatively affect our research.

\section{Materials}

Self-perceived importance of morality and competence. The perceived importance of morality and competence for participants' self-views was assessed using the three morality traits (e.g., "I consider myself to be sincere"; $\alpha=.78$ ) and the three competence traits (e.g., "I consider myself to be skilled"; $\alpha=.77$ ) identified as central descriptors of these dimensions by Leach et al. (2007).

Manipulation checks. These same traits indicating self-perceived importance of morality and competence were used to check the experimental manipulations. Perceptions of each team member's importance attached to morality were checked with three items (e.g., "Team Member A appears to be honest"; $\alpha=.91)$. Similarly, three items were used to check perceptions of the importance each team member attached to their competence (e.g., "Team Member A appears to be intelligent"; $\alpha=.84)$. An average score of the ratings of Team Member A and of Team Member B was calculated to assess the correlation between their morality ratings, $r(74)=.56, p<.001$, and their competence ratings, $r(74)=.49, p<.001$.

Team attractiveness. Five items were used to assess perceived team attractiveness (van Prooijen \& Ellemers, 2015; e.g., "I respect this team"; $\alpha=.88$ ).

Identification. Identification with the team was measured with four items (Ellemers, Spears, \& Doosje, 1999; e.g., "I identify with this team"; $\alpha=.91$ ). 
Team decision-making task. The team decision-making task was presented as a "business management task," which portrayed 10 business problems where participants had to make a trade-off between a moral solution that could jeopardize financial returns of the business and a competent solution that might compromise ethical considerations, thereby creating a binary choice for participants for each item. The solutions they had to choose from represented competing demands that were both justifiable. Some brief arguments for each solution were provided to clarify this. For example, one problem portrayed a new regional company-which specifically aimed to help women and minorities with limited qualifications on the job market- that was struggling to survive. The scenario described how this company inquired whether the organization that participants imagined working for would be willing to invest in this company. In the competent solution, the investment is not made-even though the initiative is considered important - as the financial costs are unlikely to be compensated. In the moral solution, the high-risk investment is made for ideological reasons, despite the fact that it involves substantial costs for the organization. The items used in this way represented a range of situations and decision types (regarding business investments, external communications, human resources policies, customer services) pitting competence against morality concerns in each case. The extremity of the solutions provided (e.g., the competitive aggressiveness of the competent solutions, the ethical vigilance of the moral solutions) was varied across different decisions. We took care to make sure that none of the offered solutions were explicitly immoral or incompetent in order to construct a realistic dilemma situation in which different priorities had to be weighed against each other.

Team commitment. Team commitment was assessed with three items (Bishop \& Scott, 2000; e.g., "I would be proud to tell others that I belong to this team"; $\alpha=.80$ ).

Cardiovascular measures. Impedance cardiographic (ICG) and electrocardiographic (ECG) signals were continuously recorded using a Biopac MP150 system (Biopac Systems, Goleta, CA). Blood pressure was continually measured using a Vasotrac APM205A device (Medwave, Arden Hills, MN). Acqknowledge 3.8.2 software (Biopac, Goleta, CA) was used to store the physiological data and to calculate mean arterial pressure (MAP) from the raw blood pressure readings. MAP is one of the components of TPR. The impedance cardiograms were scored (blind to condition) with VU-AMS software (AMS-IMP, Version 1.3.8.4, Free University, Amsterdam), which yielded CO. TPR was calculated from $\mathrm{CO}$ and MAP using the following formula: $\mathrm{TPR}=80 *(\mathrm{MAP} / \mathrm{CO})$. In addition to $\mathrm{CO}$ and TPR, we also calculated a combined threat-challenge index (TCI) by subtracting the standardized $z$-score of TPR from the standardized z-score of CO (Blascovich et al., 2004). Higher scores on the resulting index - which optimizes the reliability of the cardiovascular assessments (Seery, Weisbuch, Hetenyi, \& Blascovich, 2010)—indicate greater challenge (and lesser threat). In addition to CO, TPR, and TCI, heart rate (HR, derived from the ECG) and preejection period (PEP, derived from the ECG and ICG) were assessed to examine task engagement, which is a requirement to identify the experimental setting as a motivated performance situation. Task engagement is reflected in increases in HR and decreases in the PEP, compared to baseline levels.

\section{Results}

Self-perceived importance of morality and competence. One-sample $t$ tests showed that the importance participants attached to morality $(M=5.57$, $S D=0.76), t(75)=17.99, p<.001$, and to competence $(M=4.92, S D=0.72), t(75)=11.16, p<$ .001 , in their self-views was higher than the scale midpoint. Self-perceived importance of morality was somewhat higher than self-perceived importance of competence, $t(75)=6.87, p<.001$. These findings suggest that both competence and morality dimensions are considered as valued features of one's identity, as anticipated. 
Manipulation checks. The analysis of the team morality manipulation check revealed a main effect of morality, $F(1,72)=22.70, p<.001$, partial $\eta^{2}=.24$. Participants in the high-morality condition perceived their team members to be more concerned with morality $(M=5.36, S D=0.68)$ than did participants in the low-morality condition $(M=4.16, S D=1.28)$. All other effects were nonsignificant, $F<1.27, p>.26$. As intended, we obtained a significant main effect of competence on the team competence manipulation check, $F(1$, $72)=28.50, p<.001$, partial $\eta^{2}=.28$. Overall, team members were perceived to attach more value to their competence in the high-competence condition $(M=5.09, S D=0.59)$ than in the lowcompetence condition $(M=4.36, S D=0.75)$. In addition, the analysis yielded a main effect of morality on the competence manipulation check, $F(1,72)=5.71, p=.02$, partial $\eta^{2}=.07$. The perceived importance the team members attached to competence was higher in the high-morality condition $(M=4.82, S D=0.59)$ than in the lowmorality condition $(M=4.63, S D=0.91)$. No significant interaction was observed, $F=2.50, p=$ .12. The difference between the effect sizes of the main effects was tested using the procedure described by Rosnow and Rosenthal (2002). Results indicated that the effect size of the additional main effect of morality is smaller than the intended main effect of competence, $Z=2.07$, $p=.02$. Similar "spill-over" effects of information about team morality on perceived team competence have been observed in previous research (van Prooijen \& Ellemers, 2015).

Self-report measures. A MANOVA on the team attractiveness, identification, and team commitment scales yielded a multivariate main effect of morality, $F(3,70)=11.81, p<.001$, partial $\eta^{2}=.34$. Other multivariate effects were not significant, $p>.21$. Univariate effects are described next.

Team attractiveness. A univariate main effect of morality on team attractiveness emerged, $F(1,72)$ $=29.22, p<.001$, partial $\eta^{2}=.29$. As predicted, team attractiveness was perceived to be higher in the high team morality condition $(M=4.71$, $S D=0.94)$ than in the low-morality condition $(M=3.44, S D=0.99)$.

Identification. The analysis of identification revealed a univariate main effect of morality, $F(1$, $72)=31.79, p<.001$, partial $\eta^{2}=.31$. As anticipated, participants in the high team morality condition identified more with the team $(M=4.22$, $S D=1.24)$ than did participants in the low-morality condition $(M=2.71, S D=0.95)$.

Team commitment. The analysis of team commitment yielded a univariate main effect of morality, $F(1,72)=13.45, p<.001$, partial $\eta^{2}=.16$. In line with predictions, team commitment was higher in the high team morality condition $(M=$ $3.43, S D=1.03)$ than in the low team morality condition $(M=2.55, S D=0.97)$.

Task decisions. Overall, no significant main or interaction effects of team morality and team competence were obtained for the personal decision preferences expressed on task items, $F<1.89, p>.17$. This suggests that anticipated team climate did not impact personal decisionmaking. Further examination of personal choices made on individual items revealed an overall preference for moral decisions over competence decisions: In five out of 10 decisions participants indicated a preference for the moral option, $\chi^{2}>17.05, p<.001$; in one decision there was a significant preference for the competent option, $\chi^{2}=30.32, p<.001$, and in four out of 10 decisions participants did not indicate a reliable preference for either the moral or the competent option, $\chi^{2}<.84, p>.36$.

\section{Cardiovascular measures}

Analytic strategy. HR, PEP, CO, and TPR were calculated by subtracting mean cardiovascular response levels during the last minute of the baseline period from mean cardiovascular response levels during each task. ${ }^{3}$ Outliers (i.e., raw scores more than three $S D$ s from the mean) were transformed to the most extreme score observed within three SDs above or below the 
mean. ${ }^{4}$ One-sample $t$ tests were conducted to assess whether HR and PEP changed significantly from the baseline period in order to confirm that each task represented a motivated performance situation. Finally, repeated-measures ANOVAs were conducted to examine the effects of morality and competence on threat and challenge indicators during all three webcam recordings. ${ }^{5}$ Team morality and team competence were included as between-subjects factors, whereas the three webcam recordings (in which the participants allegedly engaged in a team interaction) were included as a within-subjects factor.

Task engagement. During the speech about the value participants attached to morality, HR increased significantly from baseline levels $(M=$ $18.51, S D=14.75), t(59)=9.72, p<.001$, while PEP dropped significantly $(M=-20.73, S D=$ 16.77), $t(59)=-9.58, p<.001$. Similarly, when explaining to their team members the value they attached to competence there was an increase in $\operatorname{HR}(M=11.43, S D=12.91), t(59)=6.86, p<.001$, and a decrease in PEP $(M=-16.20, S D=14.74)$, $t(59)=-8.51, p<.001$. Finally, when explaining their personal decision preferences, there was a significant increase in $\operatorname{HR}(M=14.51, S D=13.33)$, $t(59)=8.43, p<.001$, and a significant decrease in $\operatorname{PEP}(M=-14.00, S D=13.63), t(59)=-7.96$, $p<.001$. These findings confirm that participants showed sufficient motivational engagement during each of these phases of the alleged team interaction, which in turn paves the way for interpreting $\mathrm{CO}$ and TPR during these tasks in terms of challenge and threat motivational states.

Challenge and threat. No significant differences were found between the cardiovascular responses during the three webcam recordings in CO: $F<$ $.47, p>.50$, TPR: $F<1.40, p>.24$, and TCI: $F<.66, p>.42$, indicating that cardiovascular responses were similar across different phases of the alleged team interaction, that is, when describing to other team members behavioral examples indicating the importance attached to morality, the importance attached to competence, and when explaining one's preferred strategy for the decision-making task. Across all three phases of the alleged team interaction, the analyses yielded significant interactions between morality and competence on CO: $F(1,56)=17.66, p<$ .001 , partial $\eta^{2}=.24$, TPR: $F(1,49)=8.07, p=$ .007 , partial $\eta^{2}=.14$, and TCI: $F(1,49)=13.03$, $p=.001$, partial $\eta^{2}=.21$ (see Figure 1). No main effects of morality, $F<2.13, p>.15$, or competence, $F<0.74, p>.39$, were found. ${ }^{6}$

Planned contrasts showed that the "incongruent" conditions - where high value was attached to morality and low value to competence or vice versa-did not differ from each other in CO: $F=$ 0.01, $p=.92$, TPR: $F=0.69, p=.41$, and TCI: $F=0.10, p=.75$, indicating that any misalignment in morality and competence in teams elicited similar motivational responses. We then compared the two incongruent conditions with the condition where high value was attached to both morality and competence. As hypothesized, participants experienced greater threat when their team attached little value to morality or to competence than when both morality and competence were highly valued by their team, which was indicated by lower CO: $F(1,56)=12.80, p<.001$, partial $\eta^{2}=.19$, higher TPR: $F(1,49)=8.58, p=$ .005 , partial $\eta^{2}=.15$, and lower TCI: $F(1,49)=$ $13.15, p<.001$, partial $\eta^{2}=.21$.

When other team members attached equally low value to competence as well as morality, we also observed relatively more evidence of challenge than in the incongruent conditions, which was marked by higher CO: $F(1,56)=9.14, p=$ .004 , partial $\eta^{2}=.14$, and higher TCI: $F(1,49)$ $=4.20, p=.05$, partial $\eta^{2}=.08$, although no difference was observed in TPR: $F(1,49)=$ $2.35, p=.13$. The congruent conditions (when equally high or equally low value was attached to competence and morality by other team members) did not differ from each other with respect to $\mathrm{CO}: F=0.29, p=.59$, TPR: $F=1.45$, $p=.23$, or TCI: $F=1.87, p=.18$. Thus, threat appeared to be induced when there was an imbalance between competence and morality as important concerns, while more challenge emerged when other team members did not prioritize morality over competence or vice versa. 


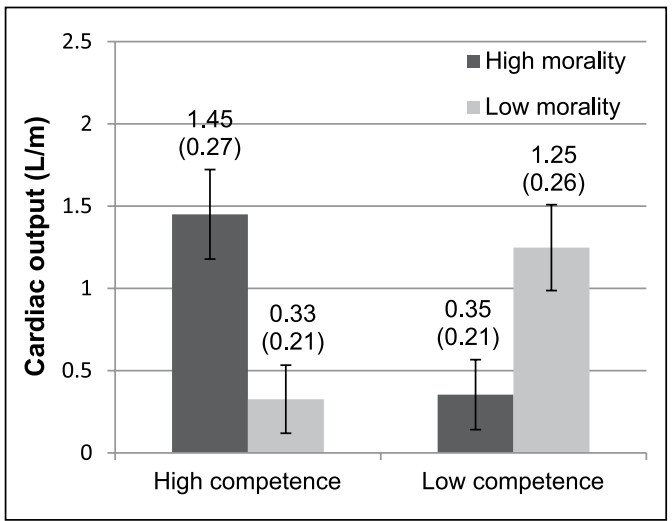

Figure 1a. Means and standard errors (in parentheses) of cardiac output across three motivated performance situations by morality and competence levels of the team.

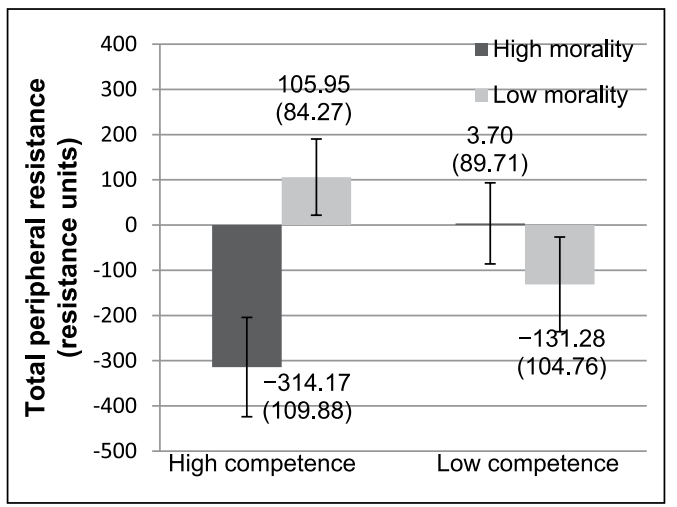

Figure 1b. Means and standard errors (in parentheses) of total peripheral resistance across three motivated performance situations by morality and competence levels of the team.

\section{Discussion}

The current research focused on how the value attached to morality and competence in task teams can affect self-reported team attractiveness and cardiovascular motivational states during team interactions. We examined this in a context where joint decisions needed to be made on competing strategies. We replicated prior findings by showing that team morality dominated different indicators of people's attraction to the team.

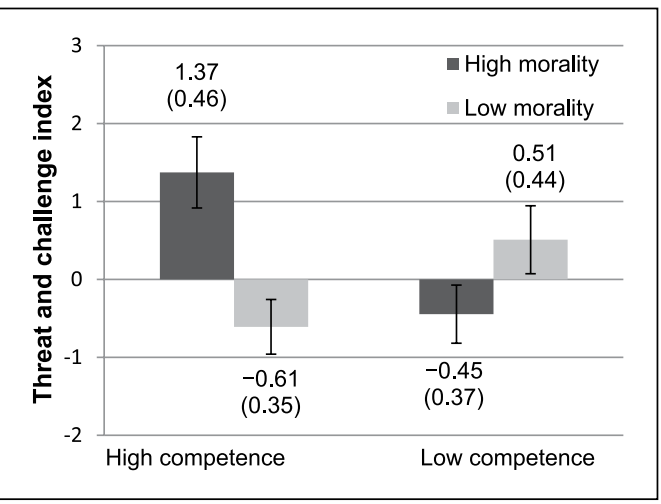

Figure 1c. Means and standard errors (in parentheses) of threat and challenge index across three motivated performance situations by morality and competence levels of the team.

Team attractiveness, identification with the team, and team commitment were all primarily affected by team morality rather than by team competence. Most importantly, we established that teams where equally high value was attached to morality as well as competence elicited a cardiovascular challenge response, while cardiovascular threat responses were observed when others prioritized either morality or competence concerns. This supports our reasoning that the match between task demands and the value attached to morality and competence by team members is an important determinant of cardiovascular motivational states, such that a weaker match is likely to evoke individual threat responses. In ambiguous team decision-making contexts-where both morality and competence concerns are vitalindividuals experience team decision-making as more demanding when there is an imbalance in the value that other team members attach to different types of concerns that are both relevant for task performance.

Interestingly, we observed a similar challenge response when team-level concerns were balanced because other team members attached equally low value to morality and competence. This situation evoked greater challenge responses than teams where different types of concerns were unbalanced. This is in line with our analysis 
in terms of balance versus imbalance between different types of concerns in the team as adding to perceived task resources versus demands implied in the situation. Thus, this suggests that threat responses in joint decision tasks indeed relate to the realization of having to compensate for the lack of balance in the importance other team members attach to the different concerns relevant to the task. Apparently, even when other team members do not particularly care about either type of concern, this makes it seem easier for the individual to consider both in making task decisions, while more individual effort and outcome uncertainty is implied when other team members clearly prioritize one concern over the other. Indeed, when neither competence nor morality is particularly valued by other team members, this can be seen to indicate that they have no a priori preferences for one or the other. Thus, they may be relatively open to arguments in favor of different preferences in each dilemma situation, indicating flexibility in relevant concerns as a situational resource relevant to individual task execution. By contrast, a misalignment between the value attached to competence versus morality in the team suggests that the team is unwilling to equally consider both aspects when making a joint decision, which consequently adds to the demands individuals have to meet to successfully complete the task of balancing competence with morality concerns.

The current findings can inform different situations in social and work life. For example, the current findings can be considered as relevant for actual business settings, in which teams have to decide about competing business strategies. Although firms are most likely to be successful when they adopt a management strategy in which ethical business conduct and performance goals converge (Carroll \& Shabana, 2010), ethical considerations cannot always be reconciled with the pursuit of business success. Other factors-such as profit orientation, the financial capacities of an organization, or legal concerns - tend to limit the opportunity to always engage in moral initiatives (Barraquier, 2011). Managers are therefore frequently confronted with a complex trade-off between financial and nonfinancial business objectives that represent competing demands, in which valid arguments are available that justify both objectives (Clegg et al., 2007; Hahn et al., 2010; Margolis \& Walsh, 2003; Vogel, 2005). Trade-offs between moral values and the need to preserve group performance can also be observed in other contexts. For example, previous research has demonstrated that supporters of political parties were willing to tolerate and support potential leaders who deviated from their in-group norm if these candidates were believed to increase the likelihood of electoral success (Morton, Postmes, \& Jetten, 2007). These findings underline the more general relevance of strategic concerns in group decision-making when task performance could suffer from an exclusive focus on normative considerations alone.

\section{Limitations and Future Directions}

A limitation of the current research is that the sample size (in particular the number of participants whose cardiovascular responses were suitable for analyses) was relatively small. Although the effects of morality and competence on cardiovascular responses were assessed across multiple measurement moments as a within-subjects factor-which in turn increases statistical power and reduces error variance (Greenwald, 1976) the robustness of the cardiovascular findings would nevertheless require replication in future studies with a larger sample.

An additional limitation of the current research is that the laboratory setting required us to employ a decision-making procedure that primarily addressed the initial stages of team collaboration, in which team members did not have the opportunity to interact with other team members and could only form an impression about the team through the self-descriptions provided by their team members. In principle, the impact of such statements about the value attached to morality and competence might diminish during later stages of team collaboration due to, for example, actual behavior displayed or the development of specific group norms. Nevertheless, 
we argue that our focus on a priori impressions is merited: Initial impressions have been shown to influence a range of affective and behavioral responses (Brambilla, Rusconi, Sacchi, \& Cherubini, 2011; Brambilla et al., 2013; Ellemers et al., 2013), which in turn can influence the decision-making process.

It can be argued that the stakes of negotiating about competing strategies in decision-making procedures are higher in real-life situations than in experimental task teams. For example, research has indicated that experiencing financial insecurity can alter people's moral integrity, such that they are more willing to cheat for financial gain and are more tolerant toward immoral behavior for financial gain of others (Sharma, Mazar, Alter, \& Ariely, 2014). In the current research there were no salient negative outcomes attached to primarily pursuing normative objectives during the decision-making process, which might have influenced the attractiveness of teams that value morality over competence. Future research could therefore explore whether the attractiveness of moral teams is attenuated in contexts that are less balanced, because strategic decisions lead to more benefits for the team than normative decisions.

With this research we have established thatwhen both types of concerns are required-an imbalance in the importance attached to competence and morality in a task team is more likely to elicit threat than balanced preferences. Future research might further examine how this relates to team members' perceptions of their ability to convince others of their self-preferred views, or the confidence they have that different aspects relevant to the task will be duly considered. In addition, while the current research focused on the anticipation of collaborating with others who prioritize competence over morality or vice versa in contexts where both features are important, future research might address how these collaborations actually unfold. For instance, it could be examined how people might adapt their post hoc rationalizations of group decisions to the stated concerns of other group members. When competence concerns dominate moral concerns in decision-making, people can rationalize their pragmatic and utilitarian approach to the decision-making by invoking moral justifications for their behavior after the fact. This is thought to help them maintain their moral self-view, and reconcile the conviction that morality is important to them with outward displays of behavior that do not seem to attest to this (see also Detert, Treviño, \& Sweitzer, 2008 and Tetlock, 2003). Future research might address how people use such post hoc motivated moral reasoning to resolve a trade-off between normative and strategic concerns in ambiguous decision-making contexts, and whether the awareness that they may do so could influence their response to an imbalance between morality and competence levels of their team members.

\section{Conclusion}

The added value of the present research beyond prior work on morality and competence in decision-making teams is that we established a discrepancy between self-reported ratings of team attractiveness (in which perceptions of the team's morality were decisive) and physiological responses during task engagement (revealing the importance of meeting situational demands by balancing both types of concerns in decision dilemmas). We think our observation that when both types of concerns are required, congruent levels of team morality and team competence promoted a more adaptive motivational state than incongruent team features is particularly noteworthy. Thus, our results show that high team morality can elicit a physiological threat response during task performance when the team attaches less value to competence as a relevant task requirement. Nevertheless, our findings also indicate that morality still functions as the primary determinant of people's feelings of attraction and commitment to the team. As a result_-when there is an imbalance between task-relevant concerns in the team-people may still be willing to engage with other team members in addressing the increased situational demands imposed by this imbalance when they are attracted and committed to the team because of the high value attached to 
morality. By contrast, they are less likely to remain committed to a team that represents a source of threat when it values competence over morality.

In sum, the current research offers new insights into the effects of different team climates on task engagement. Even though people only seem to pay attention to the morality of teams when they anticipate how inclusion in the team could influence their self-views, the interplay between competence and morality determines people's motivational states when actually working with others to resolve complex decision-making dilemmas.

\section{Funding}

The author(s) disclosed receipt of the following financial support for the research, authorship, and/or publication of this article: This research was supported by a SPINOZA grant, awarded to Naomi Ellemers.

\section{Notes}

1. Additional self-report measures were assessed that are not reported in this manuscript. A principal component analysis (PCA) revealed that the additional measures were not distinct from the team attractiveness, identification, and team commitment measures. We therefore decided to exclude these measures from the analyses.

2. A PCA was conducted to examine the distinctiveness of the self-report measures. Initial results showed that team attractiveness and identification items clustered together, but were distinct from the team commitment items. An additional PCA-in which we extracted two factors to tease apart the team attractiveness from the identification itemsrevealed that these measures formed two separate clusters, as intended. Team attractiveness and identification are sometimes considered together as evaluative (liking) versus cognitive (inclusion) aspects of the relation between the self and the group. This might account for the high correlation between these measures. However, team attractiveness is focused on how individuals judge others in a team, whereas identification is focused on whether team features are considered as a relevant part of the self. Thus, despite the high correlation between the team attractiveness and identification measures, we decided to treat these as two distinct constructs for statistical and conceptual reasons.
3. No differences between conditions in baseline measures emerged, $F<1.25, p>.30$.

4. Across the 16 cardiovascular measures (HR, PEP, CO, and TPR during the four measuring moments: baseline period and the three webcam recordings) data were transformed in eight cases.

5. Sixteen participants were excluded from the cardiovascular analyses because of poor signal quality during the ICG and ECG recordings, and five additional participants were excluded because of blood pressure equipment malfunctioning. Consequently, cardiac performance measures (i.e., HR, PEP, and CO) were analyzed for 60 participants, and the blood pressure measure (i.e., TPR) was analyzed for 55 participants, explaining differences in degrees of freedom reported.

6. Additional repeated-measures ANOVAs were conducted in which the participants' morality and competence scores were included as covariates. The interaction effects between morality and competence on CO, TPR, and TCI remained significant, which indicates that cardiovascular responses appear to be driven by a preference for balance in team features rather than by individual differences in preferences for these concerns.

\section{References}

Acqknowledge (Version 3.8.2) [Computer software]. Goleta, CA: Biopac.

Barraquier, A. (2011). Ethical behaviour in practice: Decision outcomes and strategic implications. British Journal of Management, 22, 28-46. doi:10.1111/j.1467-8551.2010.00726.x

Bettencourt, B. A., Dorr, N., Charlton, K., \& Hume, D. L. (2001). Status differences and in-group bias: A meta-analytic examination of the effects of status stability, status legitimacy, and group permeability. Psychological Bulletin, 127, 520-542. doi:10.1037//0033-2909.127.4.520

Bishop, J. W., \& Scott, K. D. (2000). An examination of organizational and team commitment in a self-directed team environment. Journal of Applied Psychology, 85, 439-450. doi:10.1037/00219010.85.3.439

Blascovich, J. (2008). Challenge, threat, and health. In J. Y. Shah \& W. L. Gardner (Eds.), Handbook of motivation science (pp. 481-493). New York, NY: Guilford Press.

Blascovich, J., \& Mendes, W. B. (2000). Challenge and threat appraisals: The role of affective cues. In J. P. Forgas (Ed.), Feeling and thinking: The role of 
affect in social cognition (pp. 59-82). Cambridge, UK: Cambridge University Press.

Blascovich, J., Mendes, W. B., Hunter, S. B., \& Salomon, K. (1999). Social "facilitation" as challenge and threat. Journal of Personality and Social Psychology, 77, 68-77. doi:10.1037/0022-3514.77.1.68

Blascovich, J., Seery, M. D., Mugridge, C. A., Norris, R. K., \& Weisbuch, M. (2004). Predicting athletic performance from cardiovascular indexes of challenge and threat. Journal of Experimental Social Psychology, 40, 683-688. doi:10.1016/j. jesp.2003.10.007

Blascovich, J., \& Tomaka, J. (1996). The biopsychosocial model of arousal regulation. In M. Zanna (Ed.), Advances in experimental social psychology (Vol. 28, pp. 1-51). New York, NY: Academic Press.

Brambilla, M., Rusconi, P., Sacchi, S., \& Cherubini, P. (2011). Looking for honesty: The primary role of morality (vs. sociability and competence) in information gathering. European Journal of Social Psychology, 41, 135-143. doi:10.1002/ejsp.744

Brambilla, M., Sacchi, S., Pagliaro, S., \& Ellemers, N. (2013). Morality and intergroup relations: Threats to safety and group image predict the desire to interact with outgroup and ingroup members. Journal of Experimental Social Psychology, 49, 811821. doi:10.1016/j.jesp.2013.04.005

Brambilla, M., Sacchi, S., Rusconi, P., Cherubini, P., \& Yzerbyt, V. (2012). You want to give a good impression? Be honest! Moral traits dominate group impression formation. British Journal of Social Psychology, 51, 149-166. doi:10.1111/j.20448309.2010.02011.x

Carroll, A. B., \& Shabana, K. M. (2010). The business case for corporate social responsibility: A review of concepts, research and practice. International Journal of Management Reviews, 12, 85-105. doi:10.1111/j.1468-2370.2009.00275.x

Clegg, S., Kornberger, M., \& Rhodes, C. (2007). Business ethics as practice. British Journal of Management, 18, 107-122. doi:10.1111/j.14678551.2006.00493.x

Detert, J. R., Treviño, L. K., \& Sweitzer, V. L. (2008). Moral disengagement in ethical decision making: A study of antecedents and outcomes. Journal of Applied Psychology, 93, 374-391. doi:10.1037/00219010.93.2.374

De Wit, F. R., Scheepers, D., \& Jehn, K. A. (2012). Cardiovascular reactivity and resistance to opposing viewpoints during intragroup conflict.
Psychophysiology, 49, 1523-1531. doi:10.1111/ j.1469-8986.2012.01456.x

Ditto, P. H., \& Lopez, D. F. (1992). Motivated skepticism: Use of differential decision criteria for preferred and nonpreferred conclusions. Journal of Personality and Social Psychology, 63, 568-584. doi:10.1037/0022-3514.63.4.568

Ellemers, N., \& Haslam, S. A. (2011). Social identity theory. In P. A. M. van Lange, A. W. Kruglanski, \& E. T. Higgins (Eds.), Handbook of theories of social psychology (pp. 379-398). London, UK: SAGE.

Ellemers, N., Kingma, L., van de Burgt, J., \& Barreto, M. (2011). Corporate social responsibility as a source of organizational morality, employee commitment and satisfaction. Journal of Organizational Moral Psychology, 1, 97-124. Retrieved from https://www. researchgate.net/publication/265440982_Corporate_Social_Responsibility_as_a_Source_of_ Organizational_Morality_Employee_Commitment_and_Satisfaction

Ellemers, N., Pagliaro, S., \& Barreto, M. (2013). Morality and behavioural regulation in groups: A social identity approach. European Review of Social Psychology, 24, 160-193. doi:10.1080/10463283.2013.84 1490

Ellemers, N., Pagliaro, S., Barreto, M., \& Leach, C. W. (2008). Is it better to be moral than smart? The effects of morality and competence norms on the decision to work at group status improvement. Journal of Personality and Social Psychology, 95, 1397-1410. doi:10.1037/a0012628

Ellemers, N., Spears, R., \& Doosje, B. (Eds.). (1999). Social identity: Context, commitment, content. Oxford, UK: Blackwell.

Fiske, S. T., Cuddy, A. J. C., \& Glick, P. (2007). Universal dimensions of social cognition: Warmth and competence. Trends in Cognitive Science, 11, 77-83. doi:10.1016/j.tics.2006.11.005

Frings, D., Hurst, J., Cleveland, C., Blascovich, J., \& Abrams, D. (2012). Challenge, threat, and subjective group dynamics: Reactions to normative and deviant group members. Group Dynamics: Theory, Research, and Practice, 16, 105-121. doi:10.1037/ a0027504

Greenwald, A. G. (1976). Within-subjects designs: To use or not to use? Psychological Bulletin, 83, 314-320. doi:10.1037/0033-2909.83.2.314

Hahn, T., Figge, F., Pinkse, J., \& Preuss, L. (2010). Trade-offs in corporate sustainability: You can't have your cake and eat it. Business Strategy and the Environment, 19, 217-229. doi:10.1002/bse.674 
Haslam, S. A., \& Ellemers, N. (2011). Identity processes in organizations. In S. J. Schwartz, K. Luyckx, \& V. L. Vignoles (Eds.), Handbook of identity theory and research (Vol. 1, pp. 715-744). New York, NY: Springer.

Leach, C. W., Ellemers, N., \& Barreto, M. (2007). Group virtue: The importance of morality (vs. competence and sociability) in the positive evaluation of in-groups. Journal of Personality and Social Psychology, 93, 234-249. doi:10.1037/00223514.93.2.234

Margolis, J. D., \& Walsh, J. P. (2003). Misery loves companies: Rethinking social initiatives by business. Administrative Science Quarterly, 48, 268-305. doi:10.2307/3556659

Morton, T. A., Postmes, T., \& Jetten, J. (2007). Playing the game: When group success is more important than downgrading deviants. European Journal of Social Psychology, 37, 599-616. doi:10.1002/ejsp.385

Nisbett, R. E., \& Wilson, T. D. (1977). Telling more than we can know: Verbal reports on mental processes. Psychological Review, 84, 231-259. doi:10.1037/0033-295X.84.3.231

Rosnow, R. L., \& Rosenthal, R. (2002). Beginning behavioral research: A conceptual primer. Upper Saddle River, NJ: Prentice-Hall.

Seery, M. D. (2011). Challenge or threat? Cardiovascular indexes of resilience and vulnerability to potential stress in humans. Neuroscience and Biobehavioral Reviews, 35, 1603-1610. doi:10.1016/j. neubiorev.2011.03.003

Seery, M. D., Weisbuch, M., Hetenyi, M. A., \& Blascovich, J. (2010). Cardiovascular measures independently predict performance in a university course. Psychophysiology, 47, 535-539. doi:10.1111/ j.1469-8986.2009.00945.x
Sharma, E., Mazar, N., Alter, A. L., \& Ariely, D. (2014). Financial deprivation selectively shifts moral standards and compromises moral decisions. Organizational Behavior and Human Decision Processes, 123, 90-100. doi:10.1016/1. obhdp.2013.09.001

Tajfel, H. (1978). Interindividual behaviour and intergroup behaviour. In H. Tajfel (Ed.), Differentiation between social groups: Studies in the social psychology of intergroup relations (pp. 27-60). London, UK: Academic Press.

Tajfel, H., \& Turner, J. C. (1979). An integrative theory of intergroup conflict. In M. A. Hogg \& D. Abrams (Eds.), Intergroup relations (pp. 94-109). Philadelphia, PA: Psychology Press.

Tetlock, P. E. (2003). Thinking the unthinkable: Sacred values and taboo cognitions. Trends in Cognitive Sciences, 7, 320-324. doi:10.1016/S13646613(03)00135-9

Van Prooijen, A. M., \& Ellemers, N. (2015). Does it pay to be moral? How indicators of morality and competence enhance organizational and work team attractiveness. British Journal of Management, 26, 225-236. doi:10.1111/1467-8551.12055

Vogel, D. (2005). The market for virtue: The potential and limits of corporate social responsibility. Washington, DC: The Brookings Institution.

VU-AMS (AMS-IMP, Version 1.3.8.4) [Computer software]. Amsterdam, the Netherlands: Free University.

Weisbuch, M., Seery, M. D., Ambady, N., \& Blascovich, J. (2009). On the correspondence between physiological and nonverbal responses: Nonverbal behavior accompanying challenge and threat. Journal of Nonverbal Behavior, 33, 141-148. doi:10.1007/s10919-008-0064-8 